\title{
Pilot test of study on brine injection into shallow formation for mitigating land subsidence in the Southern Kanto Gas Field in Japan
}

\author{
Noriyuki Muraoka $^{1}$, Yuji Hayashi ${ }^{1}$, Katsuhiro Nakamura ${ }^{1}$, Toshiaki Yamaguchi ${ }^{1}$, Kazunori Ono ${ }^{1}$, \\ Shota Kuroshima ${ }^{1}$, Akira Kurihara ${ }^{1}$, Nobuhiro Ono ${ }^{1}$, and Tsutomu Nakagawa ${ }^{2}$ \\ ${ }^{1}$ Environmental Technology Research Association for Natural Gas Dissolved in Water, \\ 1-4-1 Kasumigaseki, Chiyoda-Ku, Tokyo 100-0013, Japan \\ ${ }^{2}$ Japan Oil, Gas and Metals National Corporation (JOGMEC), 1-2-2 Hamada, \\ Mihama-ku, Chiba-city, Chiba 261-0025, Japan \\ Correspondence: Noriyuki Muraoka (n.muraoka@godoshigen.co.jp)
}

Published: 22 April 2020

\begin{abstract}
In the Southern Kanto Gas Field, natural gas dissolved in water has been produced for over 80 years. In order to produce the natural gas dissolved in water, formation water must be pumped from a reservoir in the gas field. The production of formation water is considered to be one of the causes of land subsidence.

Because brine injection into shallow formations is expected to be effective to mitigate land subsidence, our association is planning to conduct the pilot test study. In this test, the production and injection of brine are going to be performed, and we will observe a deformation of the shallow formation and a change of ground level and the bottom hole pressure. As a result of these tests, if the land subsidence mitigation effect by injection into shallow formation is confirmed, it is expected that it will be connected to increased production and to reservoir management in consideration of land subsidence mitigation in the future.
\end{abstract}

\section{Introduction}

The Southern Kanto Gas Field is the largest water-dissolved natural gas field in Japan (Fig. 1). This gas field has not only abundant reserves of natural gas dissolved in water but also a high concentration of iodine found in formation water (brine). The Southern Kanto Gas Field contributes about $30 \%$ of total world iodine production. Therefore, iodine is a precious resource for a resource-poor country like Japan.

The Southern Kanto Gas Field occurs mainly in the Boso Peninsula, and natural gas is produced from the Kazusa Group, which consists of Pleistocene age marine deposits. The Kazusa Group is composed of sandstone, mudstone, and tephra layers, and the total thickness of the Kazusa Group is approximately $3000 \mathrm{~m}$ (Kazaoka et al., 2015). The eight operation companies produce natural gas, and the annual gas production rate is about 460 million cubic meters.

On the other hand, the production of natural gas dissolved in water is considered to be one of the causes of land subsidence, because a large amount of formation water is extracted. Brine must be extracted to produce natural gas. Therefore, the amount of formation water produced is currently regulated for mitigating land subsidence. In order to enhance natural gas production, more effective methods of mitigating land subsidence are required.

From previous results, brine injection into shallow formations is expected to be effective for mitigating and controlling land subsidence (herein, the shallow formation is a non-operational reservoir overlying the production zones). To confirm the land subsidence mitigation effect, our association is planning to conduct a pilot test study.

In this paper, we will introduce the plans and progress of the pilot test study on brine injection into the shallow formation. 


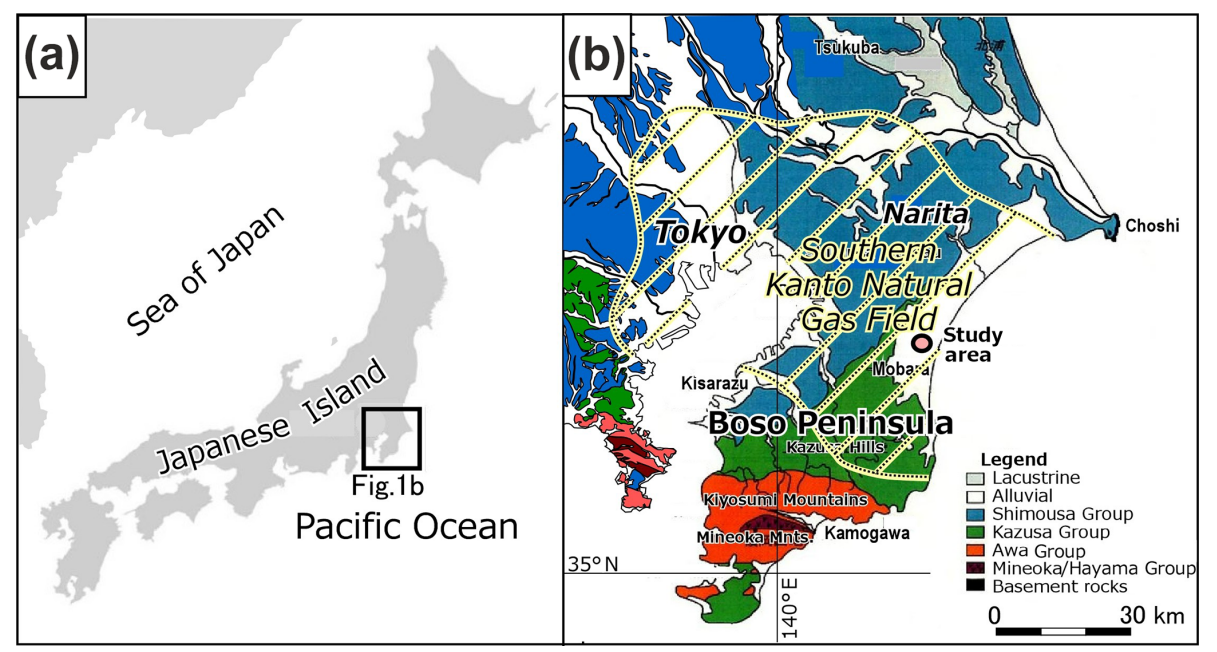

Figure 1. Location of the investigated area: (a) index map, (b) map showing the Southern Kanto Gas Field (modified from Ikeda et al., 2015, based on GSJ AIST, 2015) and GSJ geological maps as follows. Mitsunashi and Suda (1980), Mitsunashi et al. (1980), Sakamoto et al. (1987), Sudo et al. (1991), and Yoshioka et al. (2001).

\section{Pilot test plan and progress}

The location of the pilot test is shown in Fig. 1. In this pilot field test, a shallow formation exists. This shallow formation consists of the Kakinokidai and Kokumoto formations, which are member formations of the Kazusa Group. This shallow formation is a nonoperational reservoir overlying the production zones at shallow depth. Figure 2 shows an enlarged detailed site plan of the pilot test site. A natural gas production well and an injection well are located near the test site, which is completed within the operational reservoir.

In the plan of the pilot test, this shallow formation is divided into four sections (formations A, B, C, D). Six wells will be constructed, three in the $\mathrm{B}$ formation and three in the $\mathrm{D}$ formation, at the pilot test site. The purpose of this pilot test is to confirm that land subsidence can be effectively mitigated by pumping from the reservoir formation and reinjecting into the shallow formation. To evaluate the mitigation effect, the pore pressure changes and deformation of a shallower formation associated with the injection need to be monitored. To accomplish this, three types of wells are constructed in the pilot test.

- Production/injection wells. For pumping and injecting brine.

- Pressure monitoring wells. For monitoring the bottom hole pressures.

- Deformation monitoring wells. For monitoring deformation (expansion and compaction) of the shallow formation.

In the deformation monitoring wells, a continuous observation system using optical fiber technology reported by Ikeda et al. (2015) will be used (Fig. 2e).
This system can continuously observe expansion or compaction of underground formations using optical fiber.

For monitoring not only in situ deformation of the shallow formation but also ground level movement, several monitoring methods are adapted that have different measurement capabilities such as levelling, GNSS (Global Navigation Satellite System), and inclinometers (Fig. 2b, c, d). In addition, aquifer quality monitoring wells are also constructed for environmental impact assessment.

Although the pilot test has not started yet, work is currently being performed to prepare for the pilot test. This includes the following:

- Drilling two pressure monitoring wells and aquifer quality monitoring wells. Pressure monitoring wells were constructed in the B and D formations. In addition, aquifer quality monitoring wells for environmental impact assessment have been constructed.

- Conducting levelling, GNSS, and inclinometer measurements. these surveys have been conducted for getting baseline data before the start of the pilot test.

- Coring. Coring was performed for carrying out core tests to evaluate the formation property and for obtaining geological information.

\section{Characteristics of pilot test field}

Results of the field characterization are shown in Fig. 3, based on boring core samples and well logs. 


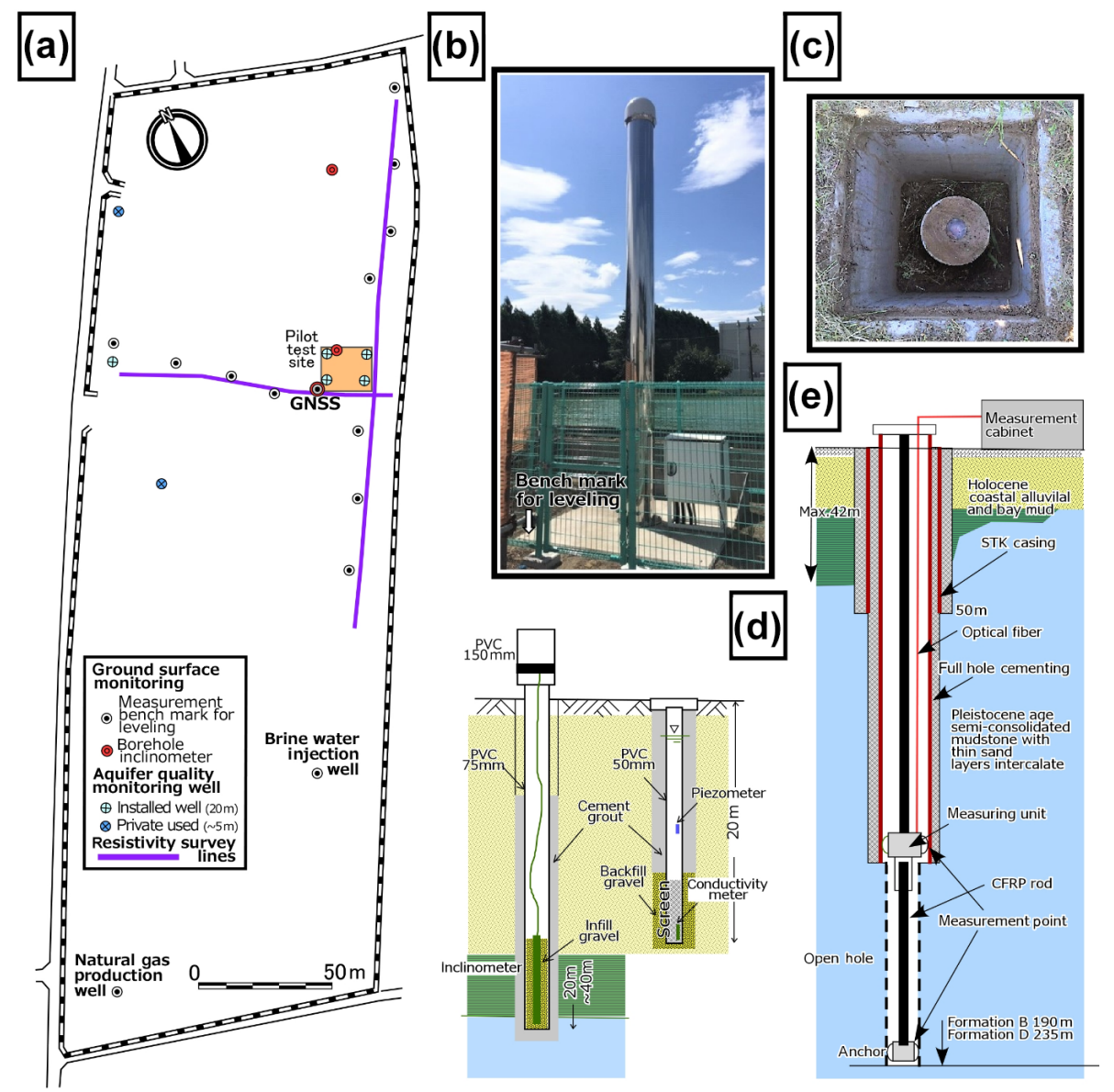

Figure 2. Map showing layout of test site with monitoring items: (a) the detailed site map, (b) GNSS, (c) the bench mark for using surface leveling, (d) the installation of inclinometer (left), the groundwater quality and piezometer monitoring well (right), (e) the formation deformation monitoring well and the measured intervals.

The upper $20 \mathrm{~m}$ depth interval consists of Holocene coastal sand. Below $20 \mathrm{~m}$ several meters of coastal valley fills clays (drowned valley fill) with mud chip detritus, which are considered the border of coastal valley. The maximum depth of the valley is estimated at $42 \mathrm{~m}$ at other drilling locations. Holocene deposits unconformably overlie the Pleistocene Kazusa Group, the Kakinokidai, the Kokumoto, and the Umegase formations.

The Kakinokidai and Kokumoto formations are expected to be our shallow target. The underlying Umegase formation is the uppermost horizon for the commercial production of natural gas.

The shallow formation is composed of mudstone with thin very fine to fine grained sand layers and pyroclastic tephra beds. A number of fractures was recognized in each $1 \mathrm{~m}$ core, by optical and CT scanned observation.

The geologic column is shown in Fig. 3. Red text indicates correlative tephra beds. The target shallow formation can be divided into four strata based on the frequency of permeable layers and fractures. The two formations B and D are selected as the completion interval.

\section{Conclusions and future work}

Moving forward, we will construct the pilot test facility and conduct the pilot test. Core tests will be also performed on the collected core samples. As a result of these tests, if the land subsidence mitigation effect by injection into the shallow formation is confirmed, it is expected that it will be connected to increased production and reservoir management in consideration of land subsidence mitigation in the future.

Data availability. For more information about the data used, please contact the corresponding author, Noriyuki Muraoka (n.muraoka@godoshigen.co.jp).

Author contributions. YH served as project leader. KN, TY, KO, $\mathrm{SK}, \mathrm{AK}, \mathrm{NO}$, and TN designed and performed the pilot test. NM prepared the manuscript with contributions from all co-authors. 


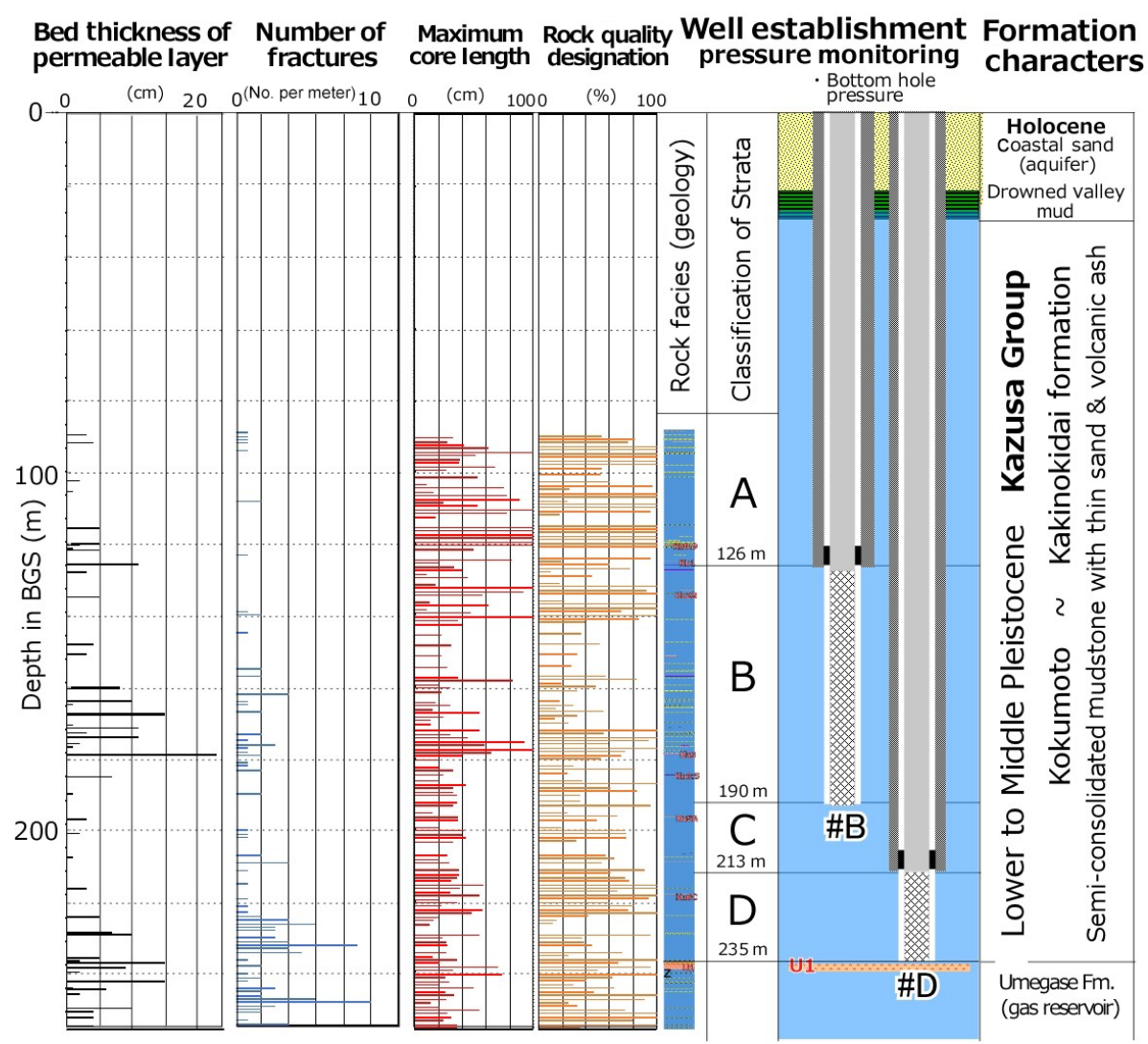

Figure 3. The formation characterization of the subsurface, the tested intervals, the overlaying aquifer, and a simplified core description are shown here. At the depth of 89-255 m continuous coring was carried out. The rock facies characterization and the four classified strata are observed.

Competing interests. The authors declare that they have no conflict of interest.

Special issue statement. This article is part of the special issue "TISOLS: the Tenth International Symposium On Land Subsidence - living with subsidence". It is a result of the Tenth International Symposium on Land Subsidence, Delft, the Netherlands, 17-21 May 2021.

Acknowledgements. This research is carried out as a joint study between the Environmental Technology Research Association for Natural Gas Dissolved in Water and the Japan Oil, Gas and Metals National Corporation (JOGMEC). We wish to thank them for permission to publish this paper.

\section{References}

GSJ AIST: Geological Survey of Japan AIST: Fuel Resource Map "Kanto Region", 2015.

Ikeda, H., Kunisue, S., Nohara D., Ooba, K., and Kokubo,

T.: In-situ formation compaction monitoring in deep reser- voirs by use of fiber optics, Proc. IAHS, 372, 393-394, https://doi.org/10.5194/piahs-372-393-2015, 2015.

Kazaoka, O., Suganuma, Y., Okada, M., Kameo, K., Martin J. H., Yoshida,T., Sugaya, M., Kameyama, S., Ogitsu, I., Nirei, H., Aida, N., and Kumai, H.: Stratigraphy of the Kazusa Group, Boso Peninsula: An expanded and highlyresolved marine sedimentary record from the Lower and Middle Pleistocene of central Japan, Quaternary Int., 383, 116-135, https://doi.org/10.1016/j.quaint.2015.02.065, 2015.

Mitsunashi, T. and Suda, Y.: Geological map of Japan, 1 : 200,000, Otaki GSJ, 1980.

Mitsunashi, T., Ono, K., and Suda, Y.: Geological map of Japan, $1: 200,000$, Yokosuka GSJ, 1980.

Sakamoto,T., Sakai, A., Hata, M., Unozawa, A., Oka, S., Hiroshima, T., Komazawa, M., and Murata, Y.: Geological map of Japan, 1 : 200,000, Tokyo GSJ, 1987.

Sudo, S., Makimoto, H., Hata, M., Unozawa, A., Takizawa, F., and Sakamoto, T.: Geological map of Japan, $1: 200$, 000, Utsunomiya GSJ, 1991.

Yoshioka, T., Fuminori Takizawa, F., Takahashi, M., Miyazaki, K., Banno, Y., Yanagisawa, Y., Takahashi, Y., Kubo, K., Seki, Y., Komazawa, M., and Hiroshima, T.: Geological map of Japan, 1 : 200,000, 2nd Edn., 2001. 